\title{
EL CONSTRUCTO TEXTUAL SÁDICO: SADE, LAMBORGHINI Y BOLAÑO $^{1}$
}

\author{
Sadistic textual construct: Sade, Lamborghini and Bolaño
}

\author{
Claire Mercier*
}

\begin{abstract}
RESUMEN
El presente artículo se propone reenfocar la discusión en torno al tema literario del sadismo por medio del análisis de tres figuras retóricas predominantes en la obra del Marqués de Sade: la metáfora, el asíndeton y la iteración. También y, sobre todo, se estudiará la transformación de estas figuras retóricas en Tadeys de Osvaldo Lamborghini y 2666 de Roberto Bolaño con el fin de entender cómo se actualiza el constructo sádico en el ámbito de la narrativa latinoamericana. Lo anterior permitirá establecer que la perversión lamborghiana reside en el hecho de considerar el sadismo como una farsa grotesca, mientras que en "La parte de los crímenes" el narrador lucha contra el sadismo mediante un rescate textual de las víctimas.
\end{abstract}

Palabras clave: sadismo, figuras retóricas, cuerpo.

\footnotetext{
${ }^{1}$ El presente artículo forma parte del Proyecto Fondecyt de Postdoctorado $2016 \mathrm{~N}^{\circ} 3160039$ : "Constructo ficcional sádico en la narrativa latinoamericana", financiado por el Fondo Nacional de Ciencia y Tecnología y patrocinado por la Pontifica Universidad Católica de Chile. La autora es la Investigadora responsable.

* Instituto de Estudios Humanísticos "Juan Ignacio Molina", Universidad de Talca. Talca, Chile. Correo electrónico: cmercier@utalca.cl.

Artículo recibido el 11 de julio de 2016. Aceptado el 24 de abril de 2017.
} 


\begin{abstract}
This article intends to refocus the discussion about the literary theme of sadism by analyzing three dominant rhetorical figures in the work of the Marquis de Sade: the metaphor, the asyndeton and the iteration. Also, and above all, the goal will be studying the transformation of these rhetorical figures in Tadeys by Osvaldo Lamborghini and 2666 by Roberto Bolaño, in order to understand how the sadistic construct is actualized in the context of Latin American narrative. This will allow to establish that the Lamborghini's perversion lies in the consideration of sadism as a grotesque farce, while in "La parte de los crímenes" case, the narrator fights against sadism by rescuing the victims textually.
\end{abstract}

Keywords: Sadism, rhetorical figures, body.

A mi me parece muy atractiva esa idea de arte y crimen: el Marqués de Sade tiene páginas magistrales [...] El crimen es un arte y, a veces, el arte es un crimen. Y yo creo que es sólo eso, no es más que eso. Roberto Bolańo (1999)

\title{
INTRODUCCIÓN
}

Las obras de Donatien Alphonse François de Sade, Osvaldo Lamborghini y Roberto Bolaño han sido mitificadas, para bien o para mal, desde el ámbito de la crítica literaria por su dimensión sádica. Con respecto a Sade, la recepción de su obra ha oscilado entre el rechazo en los enfers de las bibliotecas y la consagración de su aspecto revolucionario ${ }^{2}$. Lo mismo ha sucedido con Lamborghini y su novela póstuma Tadeys (2005), ante la cual el mismo Bolańo admite su fracaso en calidad de lector: "La empecé a leer con entusiasmo [...] y mi entusiasmo o mi inocencia de lector se vio parada en seco por la escritura del terror que me aguardaba [...] Es magnífico, es un regalo para un escritor, pero resulta ser imposible leer más de veinte páginas seguidas, a menos que uno desee contraer una enfermedad incurable" (2004, p. 142). Por su parte, la novela póstuma 2666 (2004) de Bolaño ha sido categorizada, por parte de la crítica académica, como la expresión postmoderna del mal radical. Por ejemplo, Alexis Candia, en El "paraíso infernal" en la narrativa de Roberto Bolaño (2011), establece la presencia, en 2666, de una "estética de la aniquilación" que: "[...] tiene que ver con poner en escena las múltiples formas de

\footnotetext{
${ }^{2}$ Para una lectura detallada de la recepción de la obra sadiana, véase el artículo de Marcel Hénaff: "Les Âges de la lecture sadienne" (1979).
} 
destruir totalmente al otro [...]" (47). En suma, la representación de una violencia extrema, en estas obras, ha orientado su recepción hacia lecturas mistificadoras y absolutistas donde se eclipsa la pregunta por la especificidad textual del constructo sádico, así como de sus alcances. En este sentido, lo que el presente artículo se propone es, en primer lugar, definir lo que se entiende por constructo literario sádico a partir de la especificación de sus procedimientos textuales. Para tales fines, se eligió concentrarse en tres figuras retóricas predominantes en la narrativa del Marqués: la metáfora, el asíndeton y la iteración. El corpus sadiano está constituido por Juliette ou les prospérités du vice ${ }^{3}$ (1797) y Les 120 journées de Sodome ou l'école

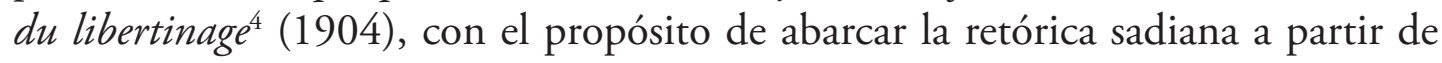
dos de sus formas literarias: la novela y un tratado semi-narrativo del sadismo. En segundo lugar, se estudiará la transformación de las tres figuras retóricas de la narrativa sadiana evocadas anteriormente en Tadeys de Lamborghini, especialmente en el episodio del Conde Marivage de Lamoir, y 2666 de Bolaño, sobre todo "La parte de los crímenes", con el fin de entender cómo se actualiza el tema del sadismo en el ámbito de la narrativa latinoamericana.

En lo que respecta al entronque de las narrativas de Lamborghini y Bolaño con Sade, se sabe que ambos escritores latinoamericanos leyeron y se inspiraron en la obra del Divino. En efecto, numerosas son las referencias al libertino francés en la obra del escritor chileno, incluso de un modo humorístico, si se toma en cuenta el personaje de Simone Darrieux en Los detectives salvajes (1998): una francesa lectora de Sade que tiene una relación de tipo sadomasoquista con Belano. Por su parte, como se verá más adelante, Lamborghini, en Tadeys, ficcionaliza claramente la figura del Divino Marqués bajo el nombre del Conde Marivage de Lamoir. No obstante, en las obras del escritor argentino y chileno, no se está en presencia de un homenaje al Marqués, sino de una intertextualidad que, empapándose del contenido sádico, reelabora el legado de uno de los referentes literarios más importante del sadismo ${ }^{5}$. En este sentido, se hace de nuevo necesario volver a los textos con el fin de saber exactamente la pertinencia de los nexos que se pueden establecer entre la narrativa de Sade, Lamborghini y Bolaño con respecto al uso del constructo textual sádico. De este modo, el artículo concluirá con la consideración sádica del cuerpo mediante el estudio de las diferencias existentes entre la alegoría farsesca de la aniquilación lamborghiana, la reivindicación de una economía

\footnotetext{
${ }^{3}$ De ahora en adelante se le nombrará Histoire de Juliette.

${ }^{4}$ De ahora en adelante se le nombrará Les 120 journées de Sodome. Con respecto a la fecha de su publicación, la primera se realiza en el ańo 1904 (Berlín) pero en base a un texto lleno de errores. Habrá que esperar hasta el año 1929 para la publicación de la versión definitiva a cargo de Maurice Heine.

${ }^{5}$ Véase el estudio literario del constructo sádico que realiza Gilles Deleuze en Présentation de SacherMasoch (1967).
} 
macabra en el caso de Sade y la crítica de este proceso en la narrativa bolañesca a través de un rescate textual de la subjetividad de las víctimas.

\section{EL CUERPO DEL DELITO}

En la narrativa sadiana, el uso de la metáfora ${ }^{6}$ evidencia la aniquilación de las víctimas. Una metáfora recurrente es la que pone el acento en la belleza física de estas últimas mediante su asociación convencional con figuras mitológicas. Por ejemplo, en Les 120 journées de Sodome, se califica a las víctimas masculinas como: "anges divins" (48), lo que establece un contraste irónico entre el retrato alegórico de estas y su función sexualmente instrumental. Además, todavía a partir de este ejemplo, cabe notar la poca individualización de las víctimas, las cuales siempre se presentan al interior de un colectivo: el de los sujetos pasivos destinados a las orgías sexuales. En este sentido, la metáfora tiene con frecuencia un sentido metonímico e incluso de cosificación. A modo de ilustración, en Histoire de Juliette, se designa a las víctimas por medio de un colectivo metonímico, los: "six culs" (988). La deshumanización y desaparición de estas últimas se encuentra también expresada por el uso de construcciones impersonales. Por ejemplo, en Les 120 journées de Sodome, durante el suplicio de Fanchon, se repite el pronombre definido "on" -que tiene aquí el valor de un pronombre impersonal (alguien) - seguido por un verbo de acción: "[...] on lui découvre les os et on lui scie en différents endroits, puis l'on découvre ses nerfs en quatre endroits formant la croix, on attache à un tourniquet chaque bout de ces nerfs, et on tourne, ce qui lui allonge ces parties délicates et la fait souffrir des douleurs inouïes" ${ }^{\prime}(371)^{10}$. Es decir que la víctima desparece por un proceso metonímico que reduce su cuerpo a las diferentes partes maltratadas. Asimismo, el libertino sádico está de alguna manera ausente de la escena-por el uso de los pronombres "on" y "lui"-, como si la tortura se estuviera realizando sin la presencia de figuras humanas: el crimen perfecto. Finalmente, el fenómeno de

\footnotetext{
6 "La metáfora [...] se ha visto como fundada en una relación de semejanza entre los significados de las palabras que en ella participan, a pesar de que asocia términos que se refieren a aspectos de la realidad que habitualmente no se vinculan [...] De ello resulta un tercer significado que posee mayor relieve y que procede de las relaciones entre los términos implicados" (Beristáin, 1985, p. 308).

7 "ángeles divinos" (trad. nuestra).

8 "seis culos" (trad. nuestra).

9 "[...] alguien expone los huesos y los corta en diferentes lugares, luego expone los nervios en cuatro lugares que forman una cruz, ata a un torniquete cada extremo de estos nervios, y gira, lo que estira estas partes delicadas y le hace sufrir [a la víctima] dolores inauditos" (trad. nuestra).

${ }^{10}$ El subrayado es nuestro.
} 
despersonalización se manifiesta a partir del uso de construcciones pronominales pasivas. En Histoire de Juliette, este tipo de construcción logra dar vida a un cadáver: "Le cadavre s'emporte"11 (661), así como a suponer que es la propia víctima quien desea su muerte: "une jeune victime [...] s'immola"12 (821). En los dos casos, la construcción pronominal pasiva hace desaparecer a los seres humanos para enfocar la narración directamente sobre la acción sádica.

En Tadeys y especialmente en el episodio del Conde Marivage de Lamoir ${ }^{13}$, la presentación de los personajes, tal como en la narrativa sadiana, se establece con respecto a su posición dentro del orden social. Por ejemplo, el nombre Knut del sirviente responde al mismo proceso de cosificación que en las obras de Sade, ya que remite a un látigo propio de Rusia. De hecho, la parodia que realiza Lamborghini de la narrativa sadiana se hace visible con la pertenencia del Conde y de su suegro a la: "Sociedad de Fanáticos de la Pija" (325), aludiendo directamente a la: "Société des Amis du Crime"14 (551) en Histoire de Juliette. No obstante, más que la aniquilación, lo que está realmente en juego en la narrativa de Lamborghini es la transformación de la identidad de las víctimas, casi exclusivamente masculinas. En Tadeys, el episodio más representativo de lo anterior es el experimento llevado a cabo en el buque-cárcel del Doctor Ky que tiene como propósito feminizar jóvenes delincuentes por medio de violaciones reiteradas. En este sentido, los calificativos que hacen referencia a las víctimas son representativos de esta particular forma de tortura sexual: "puto" (76), "mariquita" (88), "piba" (78) y "mino" (80), entre otros. De este modo, tal como el castillo de Silling en Les 120 journées de Sodome, el buque-cárcel es de alguna manera un símbolo de un cierto estado de excepción, es decir un lugar artificial cerrado en el cual la suspensión de cualquier tipo de ley permite un experimento sádico sin límite sobre el cuerpo de las víctimas. Como lo explica Gabriel Giorgi en su artículo "El crimen, el experimento, la literatura: Osvaldo Lamborghini y la naturaleza” (2008): “[...] el crimen es así una de las retóricas de la excepción soberana: no el ejercicio directo de la violencia, sino la producción de condiciones por las cuales un cuerpo es asesinable [...]" (239). Aquí, la diferencia con Sade reside en el hecho de que, en la narrativa lamborghiana, no se busca solamente escribir la violencia sobre los cuerpos, sino que también inscribirla en ellos por medio de una sexualidad sádica.

El retrato de la aniquilación de las víctimas en "La parte de los crímenes" de 2666 se caracteriza por una relativa ausencia del uso de la metáfora. No obstante, se percibe, tal como en la narrativa de Sade, una propensión metonímica con

\footnotetext{
11 "El cadáver se lleva” (trad. nuestra).

12 "una víctima joven [...] se inmoló" (trad. nuestra).

13 Personaje también presente en "'Existir, ser, estar vivo...”" (sin fecha).

14 "Sociedad de los Amigos del Crimen" (trad. nuestra).
} 
respecto a la descripción de las sevicias que sufrió cada cuerpo, sobre todo las partes que conllevan una dimensión sexual. Un ejemplo de lo anterior es la violación de Mónica Posadas y la mención sádica, por parte de los policías de Santa Teresa, de los ocho conductos por los cuales se puede violar a una mujer: el ano, la vagina, la garganta, las orejas, los ojos y el ombligo (576-577). Esta inclinación hacia la metonimia se encuentra también presente en el discurso forense, modalidad con la cual se da cuenta del estado post-mortem de los cuerpos: "La muerta [...] había sido violada anal y vaginalmente, y la muerte había sido provocada por politraumatismo craneoencefálico, aunque también había recibido dos cuchillas, una en el tórax y otra en la espalda, que la habían hecho perder sangre pero que no eran mortales de necesidad" (500). Además, la cita anterior explica la ausencia de una dimensión metafórica. En efecto, la modalidad forense imposibilita la figuración discursiva, por su función descriptiva esencialmente literal, es decir, la constancia mediante la lectura objetiva de las causas de muerte de un cuerpo. En este sentido, la objetivización de la violencia sádica que lleva a cabo el discurso médico-forense tiene como incidencia la consideración de las víctimas como cadáveres compuestos por fragmentos corporales. De este modo, se puede argüir que la ausencia de la dimensión metafórica significa, en "La parte de los crímenes", una potenciación del sadismo mediante la relación que se establece entre la frialdad prosaica de la discursividad forense y una crueldad maniática que busca aniquilar metódicamente el cuerpo de las víctimas. En definitiva, el sadismo de "La parte de los crímenes" tiene que ver con la presentación de los cuerpos como desechos de una omni-violencia sádica a través del discurso médico-forense que, por su visión desafectada, oblitera la dimensión subjetiva de los crímenes: un sadismo que se inscribe no solamente en los cuerpos, sino que también reaparece a nivel discursivo-textual.

\section{ROMPER EL LENGUAJE}

Otro recurso retórico predominante en la narrativa sadiana es el asíndeton ${ }^{15}$ que da cuenta de un intento por romper las propias reglas del lenguaje. Un ejemplo de lo anterior se encuentra en Histoire de Juliette durante una orgía sexual: “[...] mon cul devient l'unique objet de leurs caresses; tous deux le baisent, le langotent, le mordent [...]"16 (842). En la cita, la eliminación de los nexos gramaticales entre

\footnotetext{
15 "Figura de construcción opuesta al polisindeton. Afecta a la forma de las frases al yuxtaponer en series enumerativas ya sea palabras o grupos de palabras omitiendo entre ellas los nexos que las coordinan" (Beristáin: 79).

16 "[...] mi culo se convierte en el único objeto de sus caricias; ambos lo besan, lo lengüetean, lo muerden [...]" (trad. nuestra).
} 
los tres últimos verbos fragmenta la acción con el fin de reproducir el movimiento ascendente del goce sexual. De esta forma, el asíndeton manifiesta también una de las características de las escenas sexuales en las cuales la sucesión de acciones simultáneas, sobre cuerpos que se vuelven indistintos, tiende a presentar los diferentes actores de las orgías como un solo cuerpo capaz de abarcar, en un mismo momento, las varias maneras de obtener un placer sexual. En otras palabras, Sade crea retratos imposibles de una sexualidad frenética donde la fragmentación del lenguaje reproduce el intento por tocar la idea absoluta del sadismo. Lo anterior se debe además relacionar con el juego sobre los diferentes niveles del lenguaje a partir del uso de eufemismos y de perífrasis. De este modo, en Les 120 journées de Sodome, el relato de las "historiennes" 17 se refiere al semen como a una: "rosée blanche"18 (82). También, la vagina es un: "sanctuaire"19 (200) y el himen una: "fleur"20 (200). No obstante, cabe señalar que el tono "précieux" que adquiere el lenguaje sirve irónicamente, en este caso, para describir una violación, lo que permite reforzar la crueldad de la escena ${ }^{21}$. Es decir que, en la narrativa del Marqués, la violencia sádica opera también al nivel del discurso y por medio de procesos retóricos que rompen los fundamentos del lenguaje clasicista.

Al contrario, en la narrativa de Lamborghini, se está en presencia de un lenguaje a menudo vulgar, como lo muestran los siguientes términos presentes en la misma página y en el episodio del Conde de Lamoir: "mierda", "pija", "puto" y "maricas" (327). Otra diferencia sustancial reside en el hecho que, en vez de parodiar la pureza del lenguaje, Lamborghini juega con él, para obtener sin embargo el mismo resultado que Sade: una violencia retórica. En efecto, la narrativa de Lamborghini se caracteriza por ser una prosa cortada, por ejemplo, mediante una puntuación que rompe el fluir del discurso y las incisiones intempestivas, sobre todo las notas de pie de página que por su extensión en Tadeys adquieren el estatus de co-texto. Con respecto al juego con el lenguaje, este proviene sobre todo de la reducción a su aspecto literal y de la elaboración de neologismos: "el muerdealmohada Lamoir" (325) y los: "rompeculos" (325). Sin embargo, todo lo anterior introduce el mismo desfase existente en la obra de Sade entre el enunciado y su referente, pero en el caso de Lamborghini, la retórica sádica reside en el hecho de describir con un cierto tono cómico realidades abyectas.

\footnotetext{
17 "historiadoras" (trad. nuestra).

18 "rocío blanco" (trad. nuestra).

19 "santuario" (trad. nuestra).

20 "flor" (trad. nuestra).

${ }^{21}$ La contradicción entre el sentido de un enunciado y su referente podría explicar el malestar resultante de la lectura de la obra de Sade.
} 
En "La parte de los crímenes", si bien se fragmenta metonímicamente el cuerpo-cadáver a través del discurso forense, el punto de vista narrativo trata,

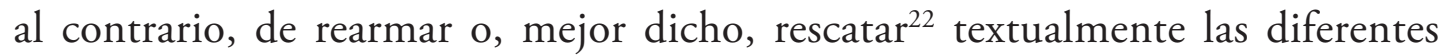
víctimas con el fin de individualizar las que "reposan" en el cementerio olvidado del año $2666^{23}$. Un ejemplo de lo anterior es la descripción de la vestimenta de las muertas y del relato de sus vidas. De este modo, detrás de la máscara forense, el narrador se emparenta con la figura del ángel benjaminiano de la Historia, en el sentido de dar a ver, por la descripción meticulosa de la historia de cada muerta, la amplitud de la masacre en Santa Teresa, con el objetivo de que estas últimas no caigan en el olvido llevado a cabo por el progreso homogéneo y amnésico de la Historia ${ }^{24}$. De hecho, en el apartado número 18 de "On the Concept of History" (c. 1940), Walter Benjamin plantea que el historiador debe experimentar la sucesión de datos históricos de la misma manera en que un creyente pasa sus manos por las cuencas de un rosario (397), en este caso, un rosario destinado a conmemorar las muertas y a dibujar la constelación de una retórica de la masacre. A modo de ilustración y retomando la figura de Mónica Posadas, en el relato del hallazgo de su cuerpo, cohabita justamente el discurso forense con la mención del punto de vista de un ángel que estaría observando, desde arriba, el cadáver:

El cuerpo, que hallaron semioculto detrás de unas cajas de cartón, estaba desnudo de cintura para abajo. Las piernas estaban manchadas de sangre. Tanta sangre que vista de lejos, o vista desde una cierta altura, un desconocido (o un ángel, puesto que allí no había ningún edificio desde el cual contemplarla) hubiera dicho que llevaba medias rojas. La vagina estaba desgarrada. La vulva y las ingles presentaban señales claras de mordidas y desgarraduras, como si un perro callejero se la hubiera intentando comer (577).

De allí una cierta ambigüedad con respecto al posicionamiento del narrador en relación con los crímenes. En efecto, la perspectiva forense reproduce un sadismo retórico de carácter aniquilador. Sin embargo, como se verá más adelante, la perspectiva forense es solamente un modo que el narrador ocupa, de forma

\footnotetext{
${ }^{22}$ En el sentido que Sergio González Rodríguez, en Campo de guerra (2014), entiende la "cartografía de las víctimas": "Al incluir a la víctima en un espacio, al espacializarla, surge un cuerpo personal en medio de un cuerpo social: una topografía cultural, una perspectiva espacial de tipo crítico. La cartografía de las víctimas que reubica el daño, menoscabo y agravio" (67).

${ }^{23}$ En relación con la descripción hecha en Amuleto (1999) de: "[...] un cementerio del año 2666, un cementerio olvidado debajo de un párpado muerto o nonato, las acuosidades desapasionadas de un ojo que por querer olvidar algo ha terminado por olvidarlo todo" (77).

${ }^{24}$ En 2666, existen también dos periodistas que intentan dar cuenta, sin mayor éxito, de la amplitud de los feminicidios en Santa Teresa: Oscar Fate y Sergio González Rodríguez.
} 
invertida, con el fin de restituir las víctimas a la esfera del lenguaje y realizar, por este medio, una crítica a las variadas dimensiones discursivas que puede revestir el sadismo $^{25}$.

\section{LOS LÍMITES DE LO DECIBLE}

El último recurso retórico de la obra del Marqués del cual se quiere dar cuenta es la iteración ${ }^{26}$ que según Philippe Sollers en L'écriture et l'expérience des limites (1968) funciona como una auto-negación del lenguaje o, en otros términos, una puesta en abismo lingüística de la negación que constituye el sadismo. La iteración se manifiesta en los cuatro niveles enunciativos de la narrativa sadiana. Primero está presente en el nivel de lo recitado, es decir el discurso filosófico previo a la escena sexual y que organiza su desarrollo o, en el caso de Les 120 journées de Sodome, el relato de las "historiennes" destinado a estimular el deseo de los libertinos. Segundo, en lo practicado que repite, mediante una orgía sexual, las ideas abstractas expuestas anteriormente. Tercero, en lo razonado, es decir el análisis de la escena sexual desde una perspectiva filosófica ${ }^{27}$. Cuarto, la inclusión de "gravures" presentes en Histoire de Juliette que representan gráficamente la escena sexual previa. En relación con los recursos de la iteración, el primero es lógicamente la enumeración, por ejemplo, la numeración final de las "pasiones” en Les 120 journées de Sodome. De este modo, la iteración, en su intento por representar el carácter absoluto de la negación, tiende a transformar el relato en un listado esquemático e irreal de las diferentes formas del sadismo. También, la iteración

\footnotetext{
${ }^{25}$ Alexis Candia, en El "paraíso infernal" en la narrativa de Roberto Bolaño, establece también una relación entre la obra de Sade y 2666 de Bolaño. No obstante, su lectura es a veces insuficiente -sobre todo en el caso del Marqués-, como cuando afirma que: "Los asesinos de 2666, como los perpetradores sadianos, entienden la relación con sus víctimas sólo a partir de la posesión y, en consecuencia, la víctima no es nada más que un objeto de placer y/o destrucción” (56). Si bien los crímenes de 2666 dan cuenta de un proceso de aniquilación sádica del Otro, se debe tomar en cuenta el elemento clave del relato: el posicionamiento del narrador, el cual intenta rescatar la individualidad de cada víctima, al contrario de la exclusiva consideración del goce sádico libertino en el caso de la narrativa sadiana.

${ }^{26} \mathrm{La}$ iteración consiste en repetir sonidos, palabras y/u oraciones. Sin embargo, a diferencia de la repetición, la iteración denota también la reiteración de determinados pasos o acontecimientos, como lo nota Helena Beristáin en su Diccionario de retórica y poética cuando se refiere a las relaciones entre la historia y el discurso: "[el] relato iterativo es aquel que narra $\mathrm{X}$ número de veces lo que ocurre una sola vez o bien varias ocurrencias muy semejantes" (467).

${ }^{27}$ Cada uno de estos tres niveles poseen repeticiones de tipo internas, por ejemplo, los listados de vicios presentes en los discursos filosóficos o la enumeración de las diferentes posturas sexuales durante las orgías.
} 
tiene que leerse en relación con el uso del superlativo, es decir lo que por definición no se puede representar, como en el siguiente ejemplo que describe las cualidades que deben tener las víctimas femeninas en Les 120 journées de Sodome: "[...] très vertueuse, très vierge et très parfaitement belle [...]"28 $(43)^{29}$. De hecho, en esta cita, la búsqueda de un absoluto, aquí de la belleza, desemboca en construcciones ilógicas y redundantes, como lo demuestra la expresión: "muy perfectamente bella”. En este sentido, la narrativa sadiana quiere alcanzar los límites del lenguaje hacia un absoluto indecible, como lo denota el uso de las exclamaciones, de los puntos suspensivos y de las onomatopeyas. En efecto, estos tres procedimientos denotan la insuficiencia del lenguaje cuando se propone describir la idea indecible -y quizás inexistente- del sadismo. En suma, la iteración, en la narrativa sadiana, denota la intención, no solamente de reiterar indefinidamente el goce sádico, sino también de exceder sus límites por medio del lenguaje, con el fin de alcanzar un más allá: una escritura del exceso que paradójicamente busca expresar la austeridad mecánica del sadismo. Así, se está en presencia de una doble contradicción: decir lo indecible del sadismo, pero dándose cuenta que el absoluto del vicio no se puede expresar mediante palabras. De este modo, el relato sadiano cae en una descripción matemática de las diferentes formas del sadismo, es decir una representación irreal que resta perversamente al sadismo el exceso de su violencia para convertirlo en la iteración monótona de sus diferentes formas.

En Tadeys, especialmente en el episodio del Conde de Lamoir, Lamborghini juega también sobre dos de los niveles iterativos de la narrativa sadiana: lo recitado y lo practicado ${ }^{30}$, como lo indica la mención de un guion que expone los diferentes pasos de la escena sexual y cuyo autor es el propio Lamoir. Además, las acciones de este guion se encuentran, tal como en Les 120 journées de Sodome, numeradas, lo que confiere al relato un cierto esquematismo. Sin embargo, la diferencia notoria con Sade es el tono humorístico de este guion, el cual se emparenta con una farsa. Por lo general, se considera la farsa como una forma degradada de la comedia, a causa de su contenido escatológico. También, por su dimensión grotesca y, por lo tanto, popular. Charles Mauron en Psychocritique du genre comique (1964) alude a las características formales de la farsa (35-36). La primera se refiere a la presencia de personajes típicos, como en el caso del episodio de Lamoir, a través de la puesta en escena del díptico amo/esclavo que se encuentra, no obstante, subvertido por la posición activa del sirviente en las escenas sexuales. La segunda característica tiene

\footnotetext{
28 “[...] muy virtuosa, muy virgen y muy perfectamente bella" (trad. nuestra).

${ }^{29}$ El subrayado es nuestro.

${ }^{30}$ Un fenómeno similar se encuentra en el episodio del buque cárcel, entre el diario del Doctor Ky que constituye el discurso racional y la puesta en acción de sus postulados científicos sobre los jóvenes delincuentes, es decir la práctica sádica.
} 
que ver con el aspecto cómico de una situación, de algunos gestos y palabras, todo lo anterior desde una perspectiva escatológica. Es precisamente lo que se presencia en el episodio del Conde de Lamoir, por ejemplo, los esfuerzos de Lamoir para proceder a la felación de su sirviente: "[...] casi se ahogó al querer tragársela, pero el muy puto lo logró. La babeó de la cabeza al tronco: era un enemigo acérrimo de las cremas y aceites. Acusaba de maricas y cobardes a quien a ellas recurría" (327). Aquí el elemento cómico reside en el registro vulgar del léxico utilizado, así como en la incongruencia de la situación, es decir los esfuerzos casi heroicos de Lamoir para poder "tragar" el pene de su esclavo. Por otra parte, Mauron se refiere a Sigmund Freud con respecto al "espíritu tendencioso" (38) de la farsa, el cual oscila entre la risa y un cierto malestar del espectador en relación con la representación de sus inhibiciones ${ }^{31}$, dando como ilustración de lo anterior autores como Voltaire o François Rabelais. De hecho, en el episodio de Lamoir, se da una suerte de tono grotesco, en el sentido que le confiere Mijaíl Bajtín en La cultura popular en la Edad Media y en el Renacimiento (1941). Un ejemplo es el tono escatológico que se hace a menudo visible a partir de la asociación del campo léxico de la sexualidad con el de la comida de tipo popular ${ }^{32}$, como cuando Lamoir describe los encuentros sexuales con su padre: "Me garchaba tres veces por lo menos, me dejaba el culo como una cacerola" (334). Finalmente, el rasgo esencial de lo grotesco, según Bajtín, es representar dos cuerpos en uno (26), lo que se puede establecer en relación con la feminización de los sujetos masculinos pasivos en la narrativa de Lamborghini, en este caso el Conde que se convierte, por medio de la sodomía, en el "puto" de su sirviente Knut. Volviendo a la referencia de Freud, en "El chiste y su relación con el inconsciente" (1905), el padre del psicoanálisis define al chiste tendencioso con respecto a su capacidad de ponerse al servicio de un propósito obsceno, agresivo o cínico (108). Sin embargo, lo más interesante reside en el hecho de que el chiste tendencioso vuelve agradable algo que el sujeto reprimiría en el ámbito de la realidad (113). En este sentido, se puede establecer una conexión entre el chiste tendencioso y el sadismo, tal como lo hace Freud a continuación: "[...] las personas que mejor hacen los chistes tendenciosos agresivos son aquellas en cuya sexualidad se registra un poderoso componente sádico, más o menos inhibido en su vida" (137). De este modo, el episodio del Conde de Lamoir, por medio del uso del tono de la farsa, pone en escena un cómico tendencioso que tiene como propósito la realización de un deseo sádico. En este sentido, todo lo que quedaría con el fin de enfrentar la supuesta naturaleza indecible del horror es justamente una risa literaria sádica, tal como lo especifica el propio autor en Tadeys:

\footnotetext{
${ }^{31}$ La oposición clásica, en términos freudianos, entre el principio de placer y el de realidad.

${ }^{32}$ Procedimiento presente en el grotesco de la Edad Media por medio de una hiperbolización sexual de ciertos alimentos, como las salchichas.
} 
"Pero la pregunta [...] sobre si un libro es 'serio', o peor: 'Si presenta un panorama objetivo', convoca la piedad. Pero no hay piedad. Hoy es el día de reírse. A espaldas del interesado" (394).

Asimismo, Bolaño opta por un relato en contra de lo indecible del sadismo a través de la descripción de su realidad. Lo anterior se concretiza por medio del mismo procedimiento retórico de la narrativa sadiana: la iteración, en este caso, del hallazgo del cadáver de una mujer y de la descripción de la violencia que sufrió su cuerpo. De hecho, se puede aplicar el modelo de los cuatros niveles presentes en la obra del Marqués a "La parte de los crímenes". En efecto, lo recitado correspondería al hallazgo del cuerpo, lo practicado a la autopsia, lo razonado al discurso de los policías de Santa Teresa que intentan en vano encontrar un(os) responsable(s) y finalmente lo mostrado residiría en la puesta en abismo de los crímenes mediante las películas snuff. No obstante, al contrario de la presencia, en los textos del Marqués, de la mirada del libertino sádico cuyo poder se materializa por el silenciamiento de las víctimas, la focalización narrativa de "La parte de los crímenes" se propone hacer visible la existencia de las víctimas al interior de un espacio discursivo propio. El episodio de los chistes machistas permite ejemplificar esta dualidad entre palabra y silencio. En efecto, se asiste, a lo largo de más de dos páginas (689-691), al listado de los chistes machistas que se cuentan los policías de Santa Teresa, paradójicamente en el contexto de los feminicidios. Es decir que se manifiesta, en relación con el discurso forense, una suerte de sadismo lingüístico o, mejor dicho, la segunda muerte, esta vez textual, de las víctimas. Sin embargo, en las últimas líneas de este episodio, se menciona a algunos policías sentados en mesas más distantes y que al contrario de participar de los chistes:

Desayunaban, como si dijéramos, acodados en la angustia y en la duda. Acodados en lo esencial que no lleva a ninguna parte. Ateridos de sueño: es decir de espaldas a las risas que propugnaban otro sueño. Por contra, acodados en los extremos de la barra, otros bebían sin decir nada, no más mirando el borlote, o murmurando qué jalada, o sin murmurar nada, simplemente fijando en la retina a los mordelones y a los judiciales (692).

En esta cita, se describe un espacio distinto ${ }^{33}$ al ambiente lingüístico-sádico de los chistes, en el cual algunos hombres, por falta de energía ante el absurdo que lo sádico expone, prefieren quedarse callados. De este modo, cabe preguntarse si el silencio de estos hombres no es el espacio a partir del cual emerge la voz del

\footnotetext{
${ }^{33}$ Es este desfase entre el espacio de los chistes y del silencio lo que confiere a este episodio una tonalidad tragicómica, es decir al contrario del tono de la farsa en Lamborghini que, por estar presente en toda la secuencia del Conde de Lamoir, permite una cierta continuidad cómica.
} 
narrador, si se piensa en la problemática que levanta Giorgio Agamben en Remnants of Auschwitz (1998) con respecto a la indecibilidad de la Shoah. En relación con lo anterior, el filósofo italiano alude al verbo griego "euphemein", el cual significa, en un contexto religioso, adorar en silencio (32). De este modo, para Agamben: "To say that Auschwitz is 'unsayable' o 'incomprehensible' is equivalent to euphemein, to adoring in silence, as one does with a god. Regardless of one's intentions, this contributes to its glory. We, however, 'are not ashamed of staring into the unsayable' - even at the risk of discovering that what evil knows of itself, we can easy find in ourselves" (32-33). Es precisamente a partir del silencio exhausto y de la mirada acusadora donde surge la voz del narrador que elige conjurar, por medio del relato de los feminicidios, la supuesta indecibilidad del sadismo. En un contexto más amplio, el narrador de los crímenes se posiciona también entre la farsa tendenciosa de Tadeys y el asesino discursivo de las víctimas en la obra del Marqués. En efecto, tanto en el caso de Sade como de Lamborghini, se está en presencia de un verdadero sadismo textual, es decir una desinhibición de la conciencia del lector con respecto a los procedimientos del sadismo. Lo anterior se materializa en Lamborghini por un tono cómico que vuelve común la violencia sádica. En Sade, la iteración produce un sentimiento de aburrimiento ante la omnipresencia textual del sadismo. Por su parte, Bolańo retoma estos dos discursos, a partir de los chistes machistas y de la perspectiva forense, pero la presencia intersticial del narrador de los crímenes rompe con la homogeneidad de estos dos modos textuales sádicos. Así, el discurso forense exhibe el cuerpo de Penélope Méndez Becerra como un cadáver: "[...] violado anal y vaginalmente, presentando numerosas desgarraduras en ambos orificios" (506). No obstante, su dignidad humana se rescata en el momento en el cual el narrador la describe como una niña tímida de once años, la única de la familia que estudiaba, sacándose además buenas notas, mientras su madre se esforzaba junto a la hermana mayor de Penélope en una maquiladora. Ambas hacían el viaje a la fábrica a pie: “[... ] entre conversaciones y risas" (505). En definitiva y según las palabras de Christopher Domínguez Michael en la entrada de su Diccionario de la literatura mexicana (19552005) (2007), Bolaño logra: “[...] conservar al mismo tiempo el honor de las víctimas y el honor de la literatura [...]” (Anales de Literatura Chilena, 2009, p. 254).

\section{CONCLUSIÓN}

El aspecto común de los tres autores corresponde a la consideración del sadismo desde el ámbito del cuerpo. Tal como en el caso de Sade, Lamborghini crea un discurso infinito de la orgía sádica, pero a partir de una visión grotesca del cuerpo. Sin embargo, al contrario de la definición, según Bajtín, del cuerpo grotesco como una celebración popular de la vida, entre las antípodas del nacimiento y de la muerte, 
Lamborghini describe irónicamente la aniquilación sádica de este cuerpo al interior de una alegría farsesca. Es decir que el cuerpo lamborghiano, tal como en la visión de la Edad Media, es un espacio de transgresión, donde la subversión llega a transformarse en una caricatura del sadismo por medio del tono cómico de su puesta en escena. Por lo tanto, el sádico se convierte en el héroe de una colectividad jovial, la cual celebra su crimen en el contexto de una fiesta popular. De este modo, se puede argüir que la retórica sádica de la obra de Lamborghini es más violenta que la del Marqués, dado que consiste en producir una risa sarcástica a partir de la realización cómica de la crueldad. El cuerpo, en la narrativa de Bolaño, se considera también bajo el signo de su aniquilación. No obstante, a diferencia de Lamborghini, se trata aquí de la figura del cuerpo cadáver. Al contrario de la visión popular del cuerpo en la Edad Media, Bolaño opera un puente entre las disecciones de Andrés Vesalio y el cuerpo autómata de René Descartes. Cabe recordar que la disección era considerada en la Edad Media como una práctica criminal, por romper la integridad del cuerpo en calidad de creación divina. No obstante, su desarrollo, durante el período del Renacimiento, instaló la aceptación del cuerpo-cadáver en calidad de objeto de estudio. Lo anterior encontró su contraparte conceptual en el Discurso del Método (1637) de Descartes, a partir de la comparación del funcionamiento del cuerpo con el de una máquina. Es en este proceso de mecanización del cuerpo que reside las primicias de su visión moderna $^{34}$. En efecto, luego de considerarse por separado del Ser, el cuerpo adquiere el estatus de máquina, lo que permite, en relación con el ideal de rendimiento de la sociedad industrial, considerarlo como una herramienta destinada a la producción en masa. El cuerpo parcelado de la narrativa sadiana se adscribe justamente a esta lógica. En efecto, cada pedazo de carne debe entregar una cierta porción de goce. De esta manera, el lenguaje sadiano busca fragmentar metonímicamente el cuerpo de las víctimas y organizar metódicamente las escenas sexuales con el fin de alcanzar la expresión de una idea absoluta del sadismo. La narrativa de Bolańo también pone en escena el cuerpo víctima de la predatoria violencia sádica a través de una lógica de acumulación de cadáveres. Sin embargo, el autor chileno se inscribe contra este preciso linaje sadiano. En efecto, el discurso de "La parte de los crímenes" logra romper con el círculo de la desinhibición sádica a través del desfase interpretativo que introduce la mirada del narrador, la cual tiene como propósito elaborar un relato necesario y crítico del horror, según las propias palabras del autor en "Literatura + enfermedad = enfermedad": "Para salir del aburrimiento, para escapar del punto muerto, lo único que tenemos a mano, y no tan a mano, también en esto hay que esforzarse, es el horror, es decir el mal" (528). Lo anterior invitaría pues a vislumbrar, detrás del narrador implicado de los crímenes, la figura de un autor implícito: Bolaño contra el sadismo.

\footnotetext{
${ }^{34}$ Véase la obra de David Le Breton: Antropología del cuerpo y modernidad (1990).
} 


\section{REFERENCIAS}

Agamben, Giorgio. Remnants of Auschwitz. The Witness and the Archive. Homo Sacer III. Trans. Daniel Heller-Roazen. New York: Zone Books, 1999.

Bajtín, Mijaíl. La cultura popular en la Edad Media y en el Renacimiento: el contexto de François Rabelais. Trad. Julio Forcat y César Conroy. Madrid: Alianza Editorial, 2003.

Benjamin, Walter. "On the Concept of History”. Selected Writings. Vol. 4: 19381940. Trans. Edmund Jephcott. Howard Eiland and Michael W. Jennings (eds.). Cambridge: Harvard University Press, (2003): 389-411.

Beristáin, Helena. Diccionario de retórica y poética. México, D. F.: Porrúa, 1995.

Bolaño, Roberto. Los detectives salvajes. Barcelona: Anagrama, 2011. Amuleto. Barcelona: Anagrama, 2011.

"Literatura + enfermedad = enfermedad". Cuentos. Llamadastelefónicas. Putas asesinas. El gaucho insufrible. Barcelona: Anagrama, (2011): 515-533. 2666. Barcelona: Anagrama, 2010.

. "Osvaldo Lamborghini: mártir". Entre paréntesis. Ensayos, artículos y discursos (1998-2003). Ignacio Echevarría (ed.). Barcelona: Anagrama, (2004): 141-142.

Una belleza nueva. Conversaciones con Cristian Warken. Entrevista grabada en La Feria Internacional del Libro (transcripción: René Rojas). Santiago, Chile: 1999. Disponible en: http://www.unabellezanueva. org/wp-content/uploads/documentos/entrevista-roberto-bolano.pdf [Consultado el 21 de enero de 2017].

Candia, Alexis. El "paraiso infernal" en la narrativa de Roberto Bolaño. Santiago, Chile: Cuarto Propio, 2011.

Deleuze, Gilles. Présentation de Sacher-Masoch avec le texte intégral de La Vénus à la Fourrure. Trad. d'Aude Willm. Paris: Les Éditions de Minuit, (2007): 7-115. 
Descartes, René. Discurso del método y meditaciones metafísicas. Trad. Manuel García Morente. Madrid: Tecnos, 2002.

Domínguez Michael, Christopher. "Bolaño, Roberto (Santiago de Chile, 1953-Barcelona, España, 2003”), Anales de Literatura Chilena, número 11 (junio 2009): 251-256.

Freud, Sigmund. Obras completas. Vol. VIII: "El chiste y su relación con el inconsciente" (1905). Trad. José L. Etcheverry. Buenos Aires: Amorrortu, 1986.

Giorgi, Gabriel. "El crimen, el experimento, la literatura: Osvaldo Lamborghini y la naturaleza”. En Brizuela, Natalia y Dabove, Juan Pablo (comps.), $Y$ todo el resto es literatura: ensayos sobre Osvaldo Lamborghini. Buenos Aires: Interzona, (2008): 233-253.

González Rodríguez, Sergio. Campo de guerra. Barcelona: Anagrama, 2014.

Hénaff, Marcel. “Les Âges de la lecture sadienne”, RIDS, 68 (novembre 1979): 2-51.

Lamborghini, Osvaldo. “Existir, ser, estar vivo...”. Novelas y Cuentos II. César Aira (ed.). Buenos Aires: Literatura Mondadori, (2011): 141-171.

Tadeys. César Aira (ed.). Buenos Aires: Sudamericana, 2005.

Le Breton, David. Antropología del cuerpo y modernidad. Trad. Paula Mahler. Buenos Aires: Nueva Visión, 2002.

Mauron, Charles. Psychocritique du genre comique. Paris: Librairie José Corti, 1964.

Sade, Donatien Alphonse François de. "Histoire de Juliette". Euvres. Vol. III. Michel Delon (éd.), Paris: Gallimard, La Pléiade, (1998): 179-1262.

. "Les 120 journées de Sodome ou l'école du libertinage". CEuvres. Vol. I. Michel Delon (éd.). Paris: Gallimard, La Pléiade, (1990): 13-383.

Sollers, Philippe. L'écriture et l'expérience des limites. Paris: Seuil, 2007. 